\title{
Inbreeding reduces fitness of seed beetles under thermal stress 10
}

\author{
Edward Ivimey-Cook ${ }^{1}$ (D) | Sophie Bricout ${ }^{2}$ | Victoria Candela ${ }^{2}$ | Alexei A. Maklakov ${ }^{1}$ | \\ Elena C. Berg ${ }^{2}$
}

\author{
${ }^{1}$ School of Biological Sciences, University \\ of East Anglia, Norwich Research Park, \\ Norwich, UK \\ ${ }^{2}$ Department of Computer Science, \\ Mathematics, and Environmental Science, \\ The American University of Paris, Paris, \\ France
}

\section{Correspondence}

Edward Ivimey-Cook, School of Biological Sciences, University of East Anglia, Norwich Research Park, Norwich, UK.

Email: E.Ivimey-Cook@uea.ac.uk

Funding information

The American University of Paris; ERC, Grant/Award Number: 724909

\begin{abstract}
Human-induced environmental change can influence populations both at the global level through climatic warming and at the local level through habitat fragmentation. As populations become more isolated, they can suffer from high levels of inbreeding, which contributes to a reduction in fitness, termed inbreeding depression. However, it is still unclear if this increase in homozygosity also results in a corresponding increase in sensitivity to stressful conditions, which could intensify the already detrimental effects of environmental warming. Here, in a fully factorial design, we assessed the lifelong impact of increased inbreeding load and elevated temperature on key life history traits in the seed beetle, Callosobruchus maculatus. We found that beetles raised at higher temperatures had far reduced fitness and survival than beetles from control temperatures. Importantly, these negative effects were exacerbated in inbred beetles as a result of increased inbreeding load, with further detrimental effects manifesting on individual eclosion probability and lifetime reproductive success. These results reveal the harmful impact that increasing temperature and likelihood of habitat fragmentation due to anthropogenetic changes in environmental conditions could have on populations of organisms worldwide.
\end{abstract}

\section{KEYWORDS}

Callosobruchus maculatus, climate change, environmental stress, fitness, inbreeding

\section{1 | INTRODUCTION}

The Earth's average annual temperature has risen by $\sim 0.85^{\circ} \mathrm{C}$ over the past 100 years (Pachauri et al., 2014; Pereira et al., 2012) with the current rate of warming nearly double that of previous decades (Pachauri et al., 2014; Pereira et al., 2012; Rosenzweig et al., 2008). One of the major contributors to this rise in annual temperature is anthropogenic greenhouse gas emissions, which have caused more than half of the observed increase in global average surface temperature from 1951 to 2010 (Pachauri et al., 2014; Pereira et al., 2012). This unprecedented rise in temperature is already affecting natural systems (Pachauri et al., 2014; Pereira et al., 2012; Trisos et al., 2020), driving many organisms to either adapt, move or go extinct (Holt, 1990; Pereira et al., 2012; Trisos et al., 2020).

In particular, a warmer and more unpredictable climate has forced many organisms, from both terrestrial and marine

Data deposited at Dryad: https://doi.org/10.5061/dryad.rv08j

This is an open access article under the terms of the Creative Commons Attribution-NonCommercial License, which permits use, distribution and reproduction in any medium, provided the original work is properly cited and is not used for commercial purposes.

(c) 2021 The Authors. Journal of Evolutionary Biology published by John Wiley \& Sons Ltd on behalf of European Society for Evolutionary Biology. 
environments, to shift geographic ranges, alter seasonal activities or migration patterns, or change interactions with other species (Barnett et al., 2001; Root et al., 2003). For instance, it is predicted that many terrestrial and freshwater species will significantly alter range boundaries and move polewards in response to anthropogenic warming as thermal tolerances are likely to be exceeded nearer the equator (Hickling et al., 2006; Thomas, 2010). Tropical organisms, which experience low variation in climactic conditions and have thus evolved narrow thermal tolerances, should be especially vulnerable to changes in range boundaries (Janzen, 1967). This shift in geographical range may also lead to corresponding changes in species interactions within ecosystems. For instance, a review comprising data from 688 published studies found significant, multitrophic effects of global environmental change acting on both mutualistic and antagonist interactions among species within an ecosystem (Tylianakis et al., 2008). Species interactions could also change as a result of altered migration patterns. For example, in response to warmer winters, several bird species have substantially reduced the migration distance between breeding and overwintering grounds (Visser et al., 2009).

A wealth of literature has also revealed how changes in climatic conditions can have cascading effects on the life history and ability of an organism to adapt to shifts in phenology (Davis \& Shaw, 2001; Gottfried et al., 2012; Muñoz et al., 2015; Norberg et al., 2012; Pearson et al., 2014; Seebacher et al., 2015). Some species are able to adapt sufficiently by undergoing rapid evolutionary change. For example, in response to a 5-year period of drought, the southern Californian plant species Brassica rapa shifted to an earlier flowering time and increased the overall duration of flowering. Subsequently, this change in flowering time then led to an increase in individual fitness as a result of escaping the harsh conditions of late-season drought (Franks \& Weis, 2008). Other species, which have been unable to adapt as quickly, have seen substantial population declines. For example, in several European bird species, warmer temperatures have resulted in phenological mismatch between breeding opportunities and food peaks (Both et al., 2006; Jiguet et al., 2007; Visser et al., 1998, 2012).

The ability of an organism to undergo rapid adaptation to novel ecological conditions such as elevated temperature is reliant on the existence of standing genetic variation within a population (Berger et al., 2020; Blows \& Hoffmann, 2005; Davis \& Shaw, 2001; Orr \& Betancourt, 2001; Willi et al., 2006). Therefore, a reduction in genetic diversity could restrict the evolvability of populations to environmental stochasticity. Climate warming and increased anthropogenic land use change (Liao \& Reed, 2009; Opdam \& Wascher, 2004) have led to habitat fragmentation (and habitat loss), which can induce genetic constraints on adaptation by increasing the levels of inbreeding (Leimu et al., 2006) as populations become more isolated. This increase in genetic homozygosity within a population often results in a significant reduction to survival and fertility through the expression of deleterious, recessive mutations (Charlesworth \& Willis, 2009; Keller \& Waller, 2002), termed inbreeding depression (Charlesworth
\& Charlesworth, 1987). Alternatively, some fraction of this inbreeding depression may result from overdominance at various fitnessrelated loci (East, 1908; Roff, 2002).

In the wild, inbreeding depression is both widespread and variable in magnitude within and between populations (Huisman et al., 2016; Keller \& Waller, 2002). Importantly for conservation biologists, this increase in inbreeding load (Kirkpatrick \& Jarne, 2000) and loss of genetic diversity (Gibbs, 2001) could potentially exaggerate a population's sensitivity to environmental stress and increase the likelihood of extinction (Bijlsma et al., 1999; Fox et al., 2006, 2011; Franke \& Fischer, 2015).

Inbred individuals may have a heightened sensitivity to increased environmental stress, through factors such as temperature, competition, nutrition, exposure to harmful chemicals, parasitism and desiccation. This sensitivity has been investigated in several species to date (See Agrawal \& Whitlock, 2010; Armbruster \& Reed, 2005; Fox \& Reed, 2011), including models systems such as the seed beetle Callosobruchus maculatus (Fox \& Reed, 2010; Fox et al., 2006, 2011; Fox \& Stillwell, 2009) and the fruit fly Drosophila melanogaster (Yun \& Agrawal, 2014). However, crucially for conservation research, the link between thermal stress and inbreeding depression remains unclear. In addition, a recent study by Yun and Agrawal (2014) highlighted that much of the link between environmental stress and inbreeding depression could be a result of density dependence (competition stress) driving the interaction.

Despite this, a recent study has shown that increasing temperature results in significantly more genome-wide de novo mutations (Berger et al., 2020). However, empirical support for a corresponding increase in inbreeding depression owing to the accumulation of these thermal stress-induced mutations is varied. For instance, in a series of studies, Fox et al. found that inbreeding depression on larval developmental traits either increased (Fox \& Reed, 2011) or decreased (Fox et al., 2011) in environments of high thermal stress. In particular, the latter experiment found that inbred individuals were detrimentally affected at the more benign temperature of $20^{\circ} \mathrm{C}$ as opposed to the higher, elevated temperatures in the previous experiment (Fox et al., 2011). Not only are the results from these experiments seemingly contradictory but they are also solely focused on measuring inbreeding depression manifesting on larval developmental traits (survival and generation time) under developmental stress.

Therefore, to fully understand the interaction between environmental stress and inbreeding depression, it is necessary to study its effect on both survival and fecundity. In addition, exposing individuals to stress across the entirety of their lifespan, and not just the developmental period, would more accurately reflect changes to environment predicted as a result of global climatic change. In light of this, and in order to address the paucity of data surrounding inbreeding depression and thermal stress, we examined the impact of inbreeding on the survival and fitness of the model system, C. maculatus, when exposed to two different lifelong rearing temperatures, one stressful and one benign. 


\section{2 | METHODS}

\section{1 | Study system}

Callosobruchus maculatus, native to Africa and Asia, is an agricultural pest that infests legumes in warehouses and in the field. Females lay their eggs on the surface of host seeds (Fox et al., 2006; Messina, 1991). Eggs hatch 4-5 days later and larvae burrow into the seed (Fox et al., 2006). Larvae develop inside the bean, and the beetles emerge as reproductively mature adults after around 2327 days. C. maculatus beetles are facultatively aphagous-that is, they are able to acquire all the water and food resources they need from the bean during larval development and do not require additional resources as adults (Messina \& Slade, 1999). In part because of the ease of laboratory rearing, $C$. maculatus has become a model organism for the study of sex differences in life history evolution (Bilde et al., 2009; Fox, 1994; Fox et al., 2006, 2007; Fritzsche \& Arnqvist, 2013; Maklakov \& Fricke, 2009).

The study population "South India USA" originated from an outbred stock population that was collected from infested mung beans (Vigna radiata) in Tirunelveli, India, in 1979. They were then moved by C. W. Fox to the University of Kentucky, USA, then to Uppsala University in 1992, and finally to the American University of Paris in 2015. The stock population is kept at aphagy (no food or water) in $1 \mathrm{~L}$ jars with $150 \mathrm{~g}$ of mung beans, and 250 newly hatched beetles are transferred to new jars with fresh beans every 23-24 days on a continual basis. The beetles are maintained in climate chambers at $29^{\circ} \mathrm{C}, 50 \%$ relative humidity and a $12: 12 \mathrm{hr}$ light:dark cycle. These laboratory conditions closely resemble their natural conditions, since their life history is adapted to a storage environment (Fox, 1994; Messina, 1991).

\section{2 | Experimental groups}

From the base population, we created four experimental treatments that differed in level of inbreeding as well as rearing temperature. The first step was to generate "inbred" (I) beetles, which were the offspring of full sibling pairs. To do this, egg-laden beans were transferred from the stock jars to virgin chambers (aerated plastic culture plates with a separate well for each individual) and monitored daily. Approximately $24 \mathrm{hr}$ after hatch, one male and one female were randomly paired together and placed in a 60-mm Petri dish with $~ 80$ beans $(N=50)$. All adults were removed $48 \mathrm{hr}$ later, and larvae were left to develop.

Before the next generation hatched, 48 egg-laden beans were moved from each Petri dish to individually labelled 48-well virgin chamber plates, which were monitored daily. Approximately $24 \mathrm{hr}$ after hatch, one sister and one brother from each 48-well plate were placed together into a 60-mm dish with $\sim 70$ beans $(N=50$ inbred pairs). Meanwhile, we created 50 "outbred" (O) pairings between randomly selected 1-day-old males and females that had hatched out of egg-laden beans (isolated in virgin chambers) from the background population. All of the inbred and outbred pairs were created on the same day.

Next, we created the four different treatment groups: outbred at the "control" temperature of $29^{\circ} \mathrm{C}(\mathrm{OC})$, outbred at the "elevated" temperature of $36^{\circ} \mathrm{C}(\mathrm{OE})$, inbred at $29^{\circ} \mathrm{C}$ (IC) and inbred at $36^{\circ} \mathrm{C}$ (IE). To do this, $\sim 24 \mathrm{hr}$ after pairing the beetles as described above, 10 egg-laden beans from each petri $(N=50$ inbred and 50 outbred dishes) were randomly selected and placed into two carefully labeled virgin chambers, five beans per virgin chamber. We selected only those beans that had eggs on them that appeared to be viable (clear, round and regularly shaped, firmly attached to the bean). One of the plates was placed into a climate chamber kept at the control temperature $\left(29^{\circ} \mathrm{C}\right)$, and the other plate was placed in a chamber set to "elevated" temperature $\left(36^{\circ} \mathrm{C}\right)$. This higher temperature was selected because it represents the upper limit of what the beetles can withstand without devastating impacts on fertility or lifespan (Rogell et al., 2014). Humidity and light: dark cycles were kept the same for both chambers: 50\% humidity and 12:12 hr light:dark. Virgin chambers were monitored daily.

\section{3 | Daily fecundity and lifespan assays}

We monitored the virgin chambers every day and recorded the hatch date and sex of all eclosed offspring from the four treatments. One day after hatch, we paired the offspring with a 1-day old beetle of the opposite sex from the background population. Similar to previous steps of the experiment, virgin background beetles were generated by putting egg-laden beans from the control jars into virgin chambers, and hatch was monitored daily. Pairs were moved at the same time every day from one Petri dish to another for 5 days.

On the day of pairing (D0), the male and female were placed in a 60-mm Petri with 65 beans. Females can lay up to 65 eggs per day (E. C. Berg, unpublished data), and we wanted to provide enough beans so that no more than one egg would be laid on each bean. On subsequent days (D1, D2, D3 and D4+), pairs were moved to 35-mm Petri dishes with $30-50$ beans (egg-laying declines with age). Once the pairs were moved to the final dish in the series, they were monitored daily. If at any point the female was found dead, pairs were obviously not transferred further. All dead individuals were removed immediately, and dates of death were recorded.

To calculate daily fecundity, we recorded the number of eclosed offspring per dish per target individual. Approximately 35 days after eggs were laid, we froze the dishes to facilitate counting of eclosed offspring.

\section{4 | Statistical analyses}

All analyses were performed using R v4.0.3 (R Core Team, 2019). Four distinct measures of reproduction were analysed using the GLMMTMB v1.0.2.9000 package (Brooks et al., 2017; Magnusson et al., 2019) and contained the main effects of "Breeding status" 


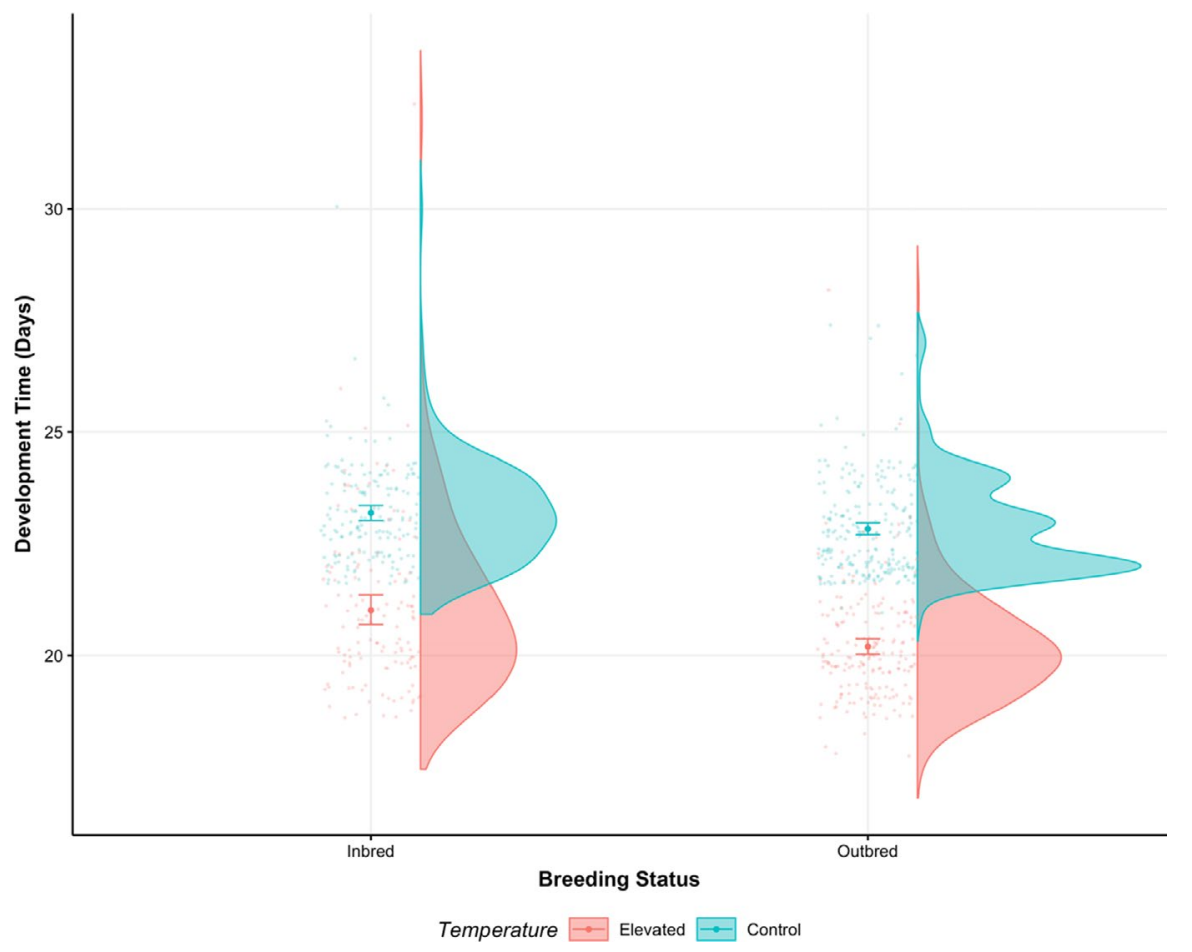

FIGURE 1 Development time of inbred and outbred populations at control (blue) and elevated (red) temperatures. Points with error bars represent mean values with $95 \%$ confidence intervals. Marginal violin plots show the relative distribution of raw data

(inbred or outbred) and "Temperature regime" (control or elevated) and the subsequent higher-order interaction. In addition, all models contained the random effect of "Parent ID" in order to account for pseudoreplication of individuals from the same parent. For agespecific reproduction, additional fixed effects of Day and Day ${ }^{2}$ and an additional random effect of "Individual ID" was added, nested within "Parent ID," in order to account for repeatedly measuring the same individual over time.

Whilst the fixed and random effect structure remained similar for each measure, the distributions of the responses differed slightly. 1. Eclosion success was a binary response, where individuals either hatched (1) or did not (0). 2. For both age-specific reproduction and lifetime reproductive success (LRS), data was analysed in a two-step process. Firstly, a full Poisson model and a Poisson model with an observation level random effect was fitted and the residuals simulated using the DHARMA v0.3.3.0 package (Hartig, 2020). If zero-inflation was detected within these residuals, an additional zero-inflation component and a variety of error distributions were fitted. Model selection was then performed to select the best fitting error distribution and zero-inflation parameters for each measure, chosen as the model with the lowest Akaike's information criterion (AIC). 3. The last measure was individual fitness, or $\lambda$ ind, which represented the dominant eigenvalue of an age-structured Leslie matrix (Leslie, 1945) calculated using the POPBIO v2.7 package (Stubben \& Milligan, 2007). For each matrix, the top row denoted age-specific fertility whilst the subdiagonal represented survival probability from age $t$ to $t+1 ; 18-32$ days were also added to the start of the fertility schedule, which corresponded to egg-adult development time under the various breeding and temperature treatments. These individual fitness values were then analysed with a similar model structure to above, albeit with a Gaussian error structure.
For each measure, the overall effect of "Breeding status," "Temperature regime" and the interaction between the two, was identified using the ANOVA function from the CAR v3.0-10 package. In addition, data was either visualised using the GGPLOT2 v3.3.3 package (Wickham, 2009) or on bootstrapped estimation plots from the DABESTRV0.3.0 package (Ho et al., 2019). Estimated marginal means were reported using the EMMEANS v1.5.5-1 package (Lenth et al., 2019).

Lastly, we analysed how "Temperature regime" and "Breeding status" influenced survival. For this, we used mixed effects cox proportional hazards models from the coXME package v2.2-16 (Therneau, 2012) and fit similar models to above. Hazard ratios were then visualised with forest plots created using GGPLOT2.

\section{3 | RESULTS}

\section{1 | Development time}

Development time was significantly influenced by breeding status, temperature regime and the interaction between the two $\left(\chi^{2}\right.$ $(1)=5.25, p=.022, \chi^{2}(1)=480.75, p<.001$ and $\chi^{2}(1)=6.49, p=.011$, respectively; Figure 1). In particular, outbred individuals had a significantly quicker development time in comparison to inbred individuals (Outbred $=21.5$ days; Inbred $=22.1$ days; Difference $=-0.56$, $p<.001$, Figure 1, Table S1A). As expected, individuals at elevated temperatures developed quicker than those in the control regime (Control $=23.0$ days; Elevated $=20.6$ days; Difference $=-2.44$, $p<.001$, Figure 1, Table S1A). Importantly, the detrimental effects of increased inbreeding load were exacerbated at higher temperatures (OC (22.8 days) - IC (23.2 days): Difference $=-0.348, p=.02 ;$ OE 
FIGURE 2 Eclosion success in inbred and outbred populations at control (blue) and elevated (red) temperatures. Points between 0 and 1 represent mean values with $95 \%$ confidence intervals
FIGURE 3 Age-specific reproduction of inbred (dot-dash) or outbred (solid) individuals in elevated (red) or control (blue) temperatures. Points represent means with accompanying $95 \%$ confidence intervals
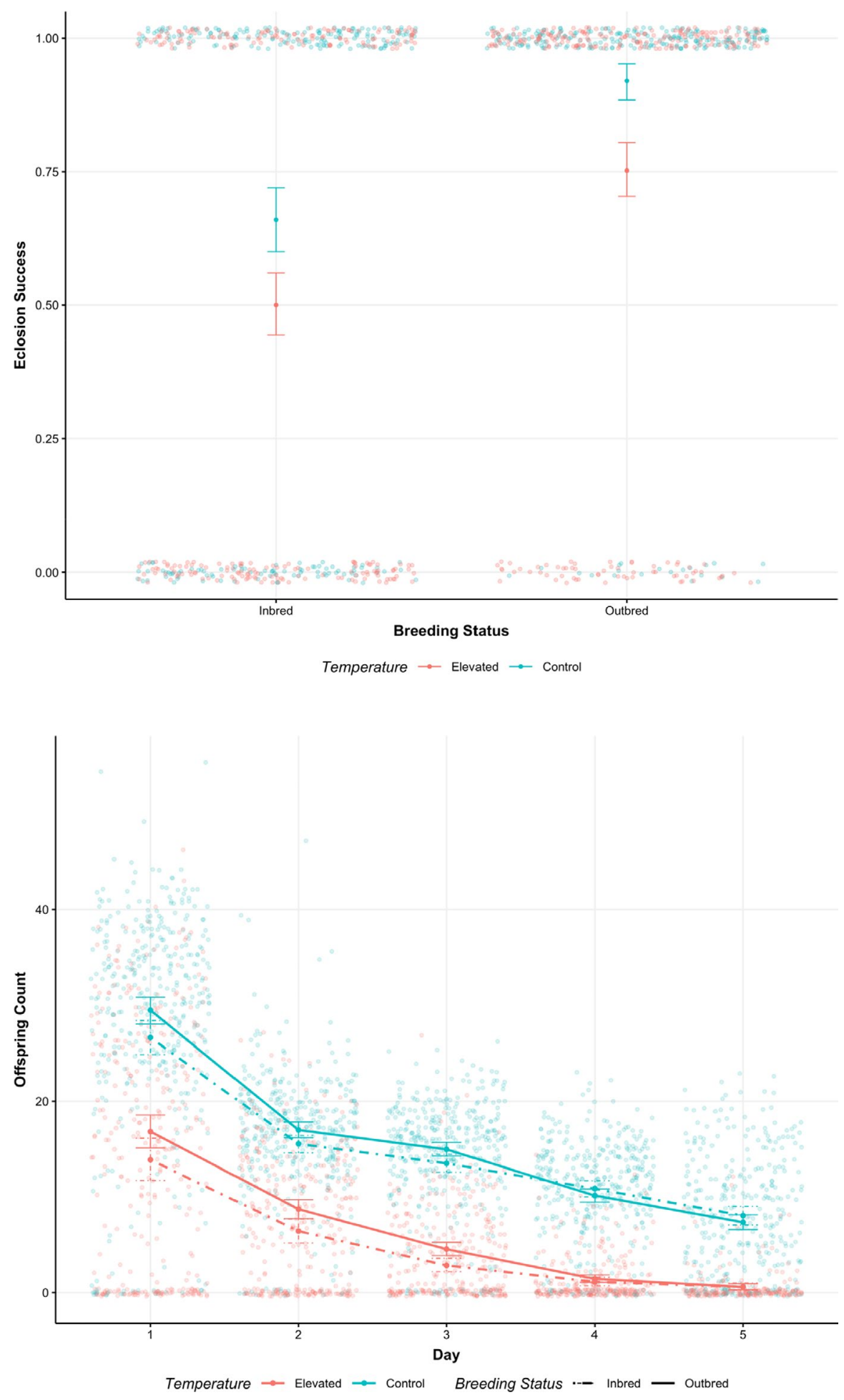

(20.2 days) - IE (21.1 days): Difference $=-0.831, p<.001 ;$ Figure 1 , Table S1B/C).

\section{2 | Eclosion success}

Eclosion success was significantly influenced by breeding status, temperature regime and the interaction between the two $\left(\chi^{2}\right.$
(1) $=35.94, p<.001: \chi^{2}=25.09, p<.001: \chi^{2}(1)=3.89$ and $p=.049$, respectively; Figure 2). More specifically, eclosion success was higher in individuals that were outbred and had a decreased inbreeding load (Outbred $=87 \%$; Inbred $=59 \%$; Odds ratio $=4.50$, $p<.001$; Table S2A) or were exposed to control temperatures and to a less stressful environment (Control $=84 \%$; Elevated $=66 \%$; Odds ratio $=2.67, p<.001$; Table S2A). This interaction resulted in outbred individuals raised at control temperatures having the greatest 
eclosion success in comparison to other treatments (OC (94\%) - OE (78\%): Odds ratio $=4.19, p<.001$; IE $(50 \%)$ : Odds ratio $=14.64$, $p<.001$; IC (68\%): Odds ratio = 6.91, $p<.001$; Figure 2; Table S2B/C).

\section{3 | Reproduction}

Age-specific reproduction, LRS and $\lambda$ ind were all significantly influenced by temperature (ASR: $\chi^{2}(1)=5.16, p=.023$; LRS: $\chi^{2}(1)=279.75$, $p<.001 ; \lambda$ ind: $\chi^{2}(1)=36.57, p<.001$; Figures $3-5$, Tables S3A-5C) but not breeding status, with no significant difference detected between outbred and inbred individuals (ASR: $\chi^{2}(1)=0.003, p=.958$ : LRS: $\chi^{2}(1)=0.145, p=.703$; $\lambda$ ind: $\chi^{2}(1)=0.988, p=.320$; Figures $3-$ 5 , Tables $\mathrm{S} 3 \mathrm{~A}-5 \mathrm{C})$. In all cases, elevated temperature was associated with decreased fitness (LRS: Control $=80.0$; Elevated $=36.1$, Ratio $=2.22, p<.001 ; \lambda$ ind: Control $=1.13 ;$ Elevated $=0.88$,

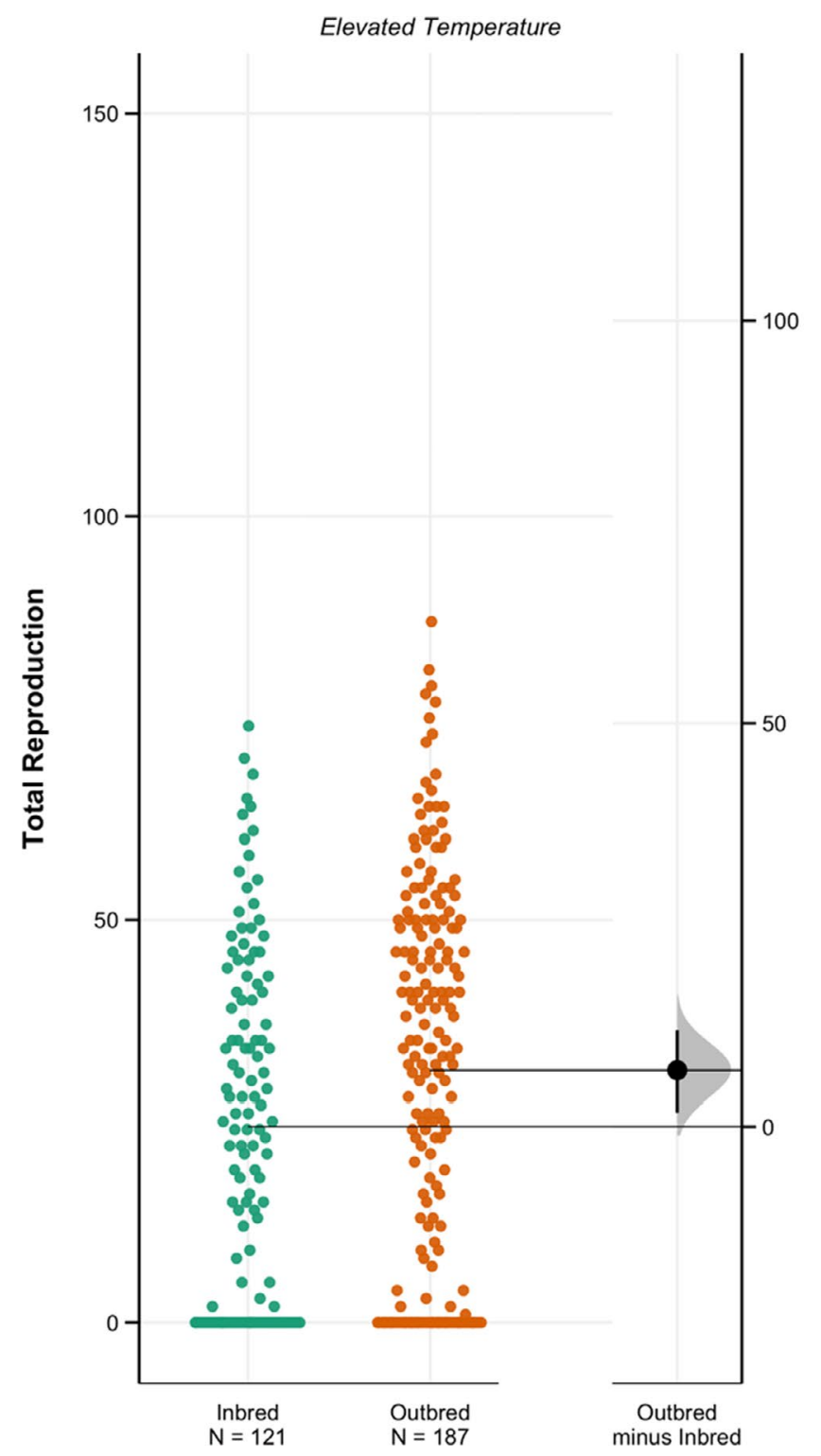

Estimate $=0.25, p<.001$; Figures 4 and 5, Tables S4A and 5C). Importantly, differences in LRS between inbred and outbred individuals only manifested at elevated temperatures (LRS interaction: $\chi^{2}(1)=4.08, p=.043$; Figure 4, Table S4A-C), where the negative effects of higher temperatures were exacerbated by increased inbreeding load (OC (80.7) - IC (79.6): Ratio = 1.01, $p=.704$; OE (38.5) - IE (32.7): Ratio = 1.18, $p=.02$; Figure 4, Table S4A-C). No significant interaction between temperature and breeding status was detected for ASR $\left(\chi^{2}(1)=0.429, p=.512\right)$ and $\lambda$ ind $\left(\chi^{2}(1)=0.373\right.$, $p=.541$; Figures $3-5$, Tables S3A-C and S5A-C).

\section{4 | Survival}

Individual survival was significantly affected by temperature regime $\left(\chi^{2}(1)=183.03, p<.001\right)$ but not breeding status $\left(\chi^{2}(1)=0.981\right.$,

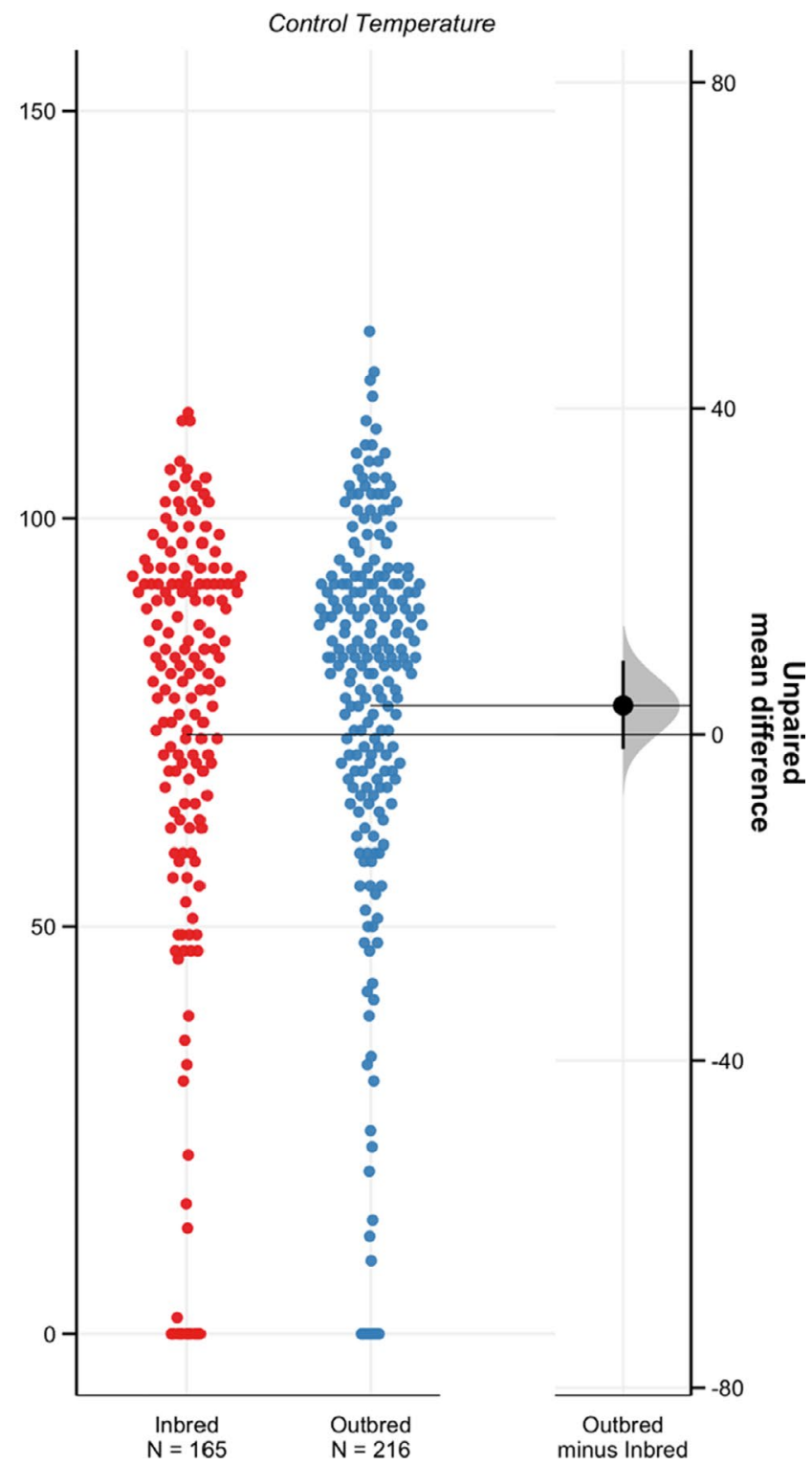

FIGURE 4 Total reproduction (LRS) between inbred and outbred individuals at elevated (left) and control (right) temperatures. Each panel shows the raw data and bootstrapped mean differences between treatments with $95 \%$ confidence intervals 

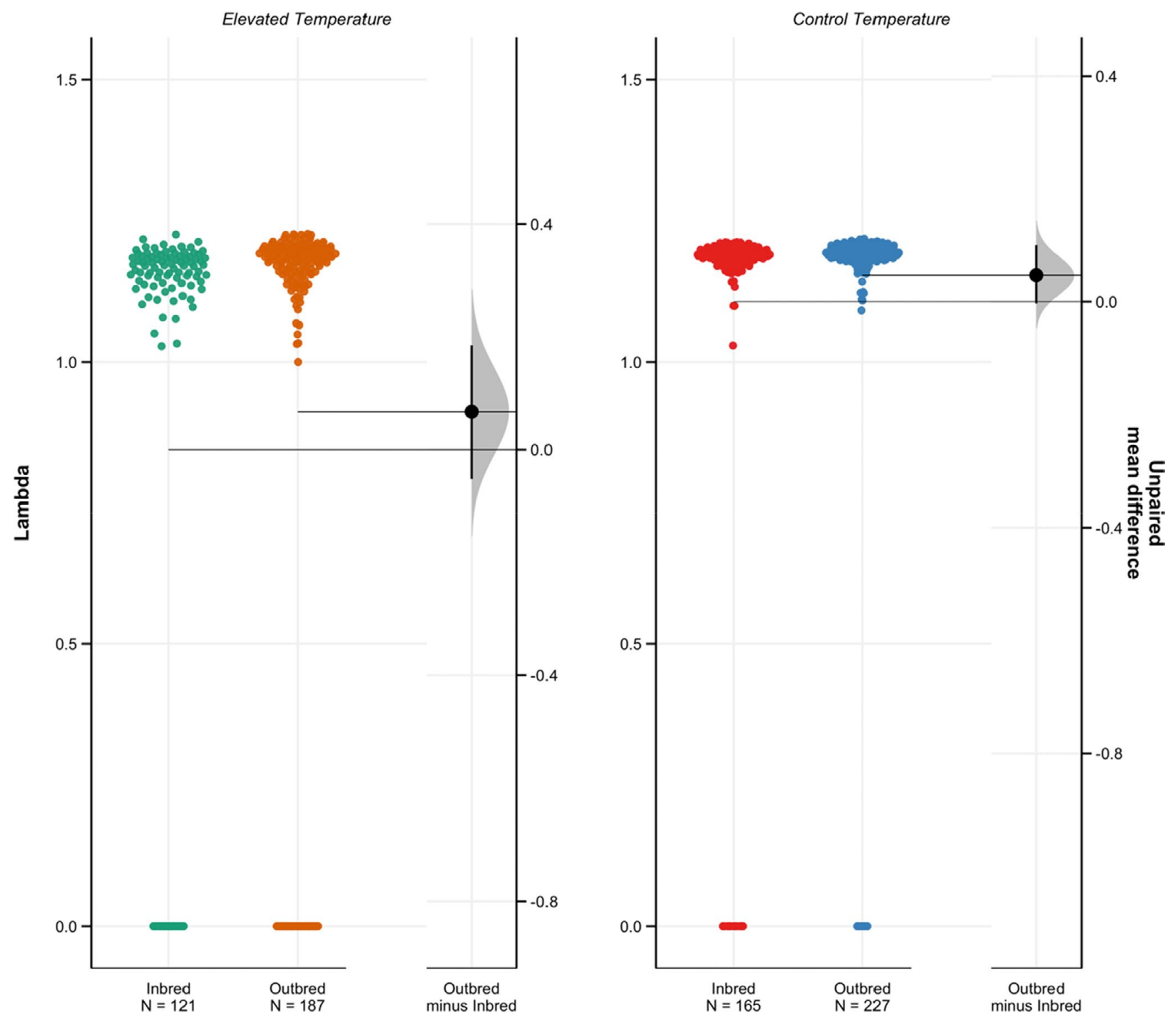

FIGURE 5 Individual fitness of inbred and outbred individuals at elevated (left) and control (right) temperatures. Each panel shows the raw data and bootstrapped mean differences between treatments with $95 \%$ confidence intervals

$p=.322)$ or the interaction between the two $\left(\chi^{2}(1)=0.929\right.$, $p=.335)$. Individuals raised at control temperatures have reduced mortality risk and thus longer lifespans in comparison to those from elevated temperatures regardless of breeding status (OC-IC: Estimate $=0.012, p=.906$; OC-OE: Estimate $=-1.197, p<.001 ;$ OCIE: Estimate $=-1.030, p<.001$; OE-IE: Estimate $=0.167, p=.169$; Figure 6, Table S6A/B).

\section{4 | DISCUSSION}

Our results provide compelling evidence to suggest that increased inbreeding load exacerbates the negative effects of elevated temperature on various measures and components of fitness in this population of $C$. maculatus. Specifically, we found that increasing temperature and thus exposure to environmental stress had large negative effects on five of six measured life history traits. This result alone is unsurprising, as previous work in the same species of beetle has reported similar detrimental effects of high temperature, including reduced reproductive fitness and longevity (Berger et al., 2017; Rogell et al., 2014), but also on the increase of genome-wide de novo mutations (Berger et al., 2020). Only on development time was the effect of increasing temperature less obvious. On one hand, faster development time with elevated temperature could be seen as adaptive, as earlier breeding positively influences rate-sensitive fitness (Sibly \& Calow, 1986). Under some circumstances, this could compensate for reduced LRS by increasing $\lambda$ ind. However, as this measure $(\lambda i n d)$ is entirely dependent on the amount of pre-reproductive time prior to fertility, the variation in development time due to temperature (ranging from 18 to 32 days) has little impact on the individual fitness value calculated (see Green \& Painter, 1975). This is perhaps one reason why we do not see as great a difference in 


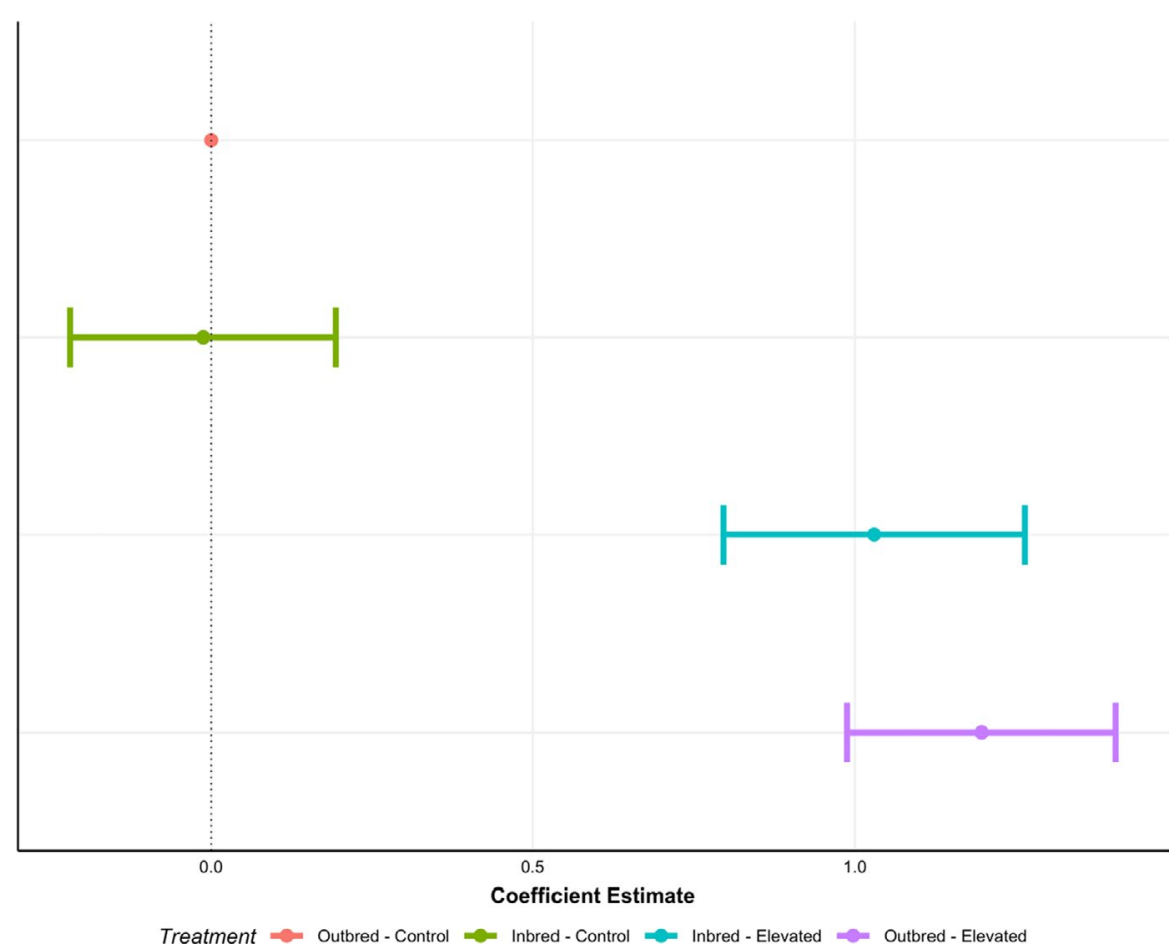

FIGURE 6 Survival coefficients from a mixed effects cox model with accompanying $95 \%$ confidence intervals. Outbred-Control is the reference value at 0 . Values to the left reflect mortality decrease and increased longevity, values to the right represent a mortality increase and decreased longevity $\lambda$ ind as with LRS. On the other hand, faster development could also be maladaptive, particularly if the increased growth rate results in higher mortality and reduced body size, which will contribute to reduced fecundity (Sibly \& Calow, 1986; Sibly et al., 1985). Only when a species becomes adapted to a particular thermal regime (Rogell et al., 2014) or if the environment between parents and offspring is predictable (Lind et al., 2020; Sibly \& Calow, 1986) do the harmful effects of increasing temperature begin to subside. However, in contrast to previous work (Yun \& Agrawal, 2014), we found that thermal stress, in the absence of any form of density dependence, was sufficient in magnitude to result in increased inbreeding depression on development time, eclosion probability, and LRS. We note that the magnitude of this exacerbation and the general effects of inbreeding were largely trait-dependent, which suggests that not all fitness components respond in an analogous manner to environmental stress and inbreeding (Springer et al., 2020).

This result is similar in trend to the positive correlation between developmental stress and larval mortality found in several studies in the same organism (Fox \& Reed, 2011; Springer et al., 2020). Similarly, a recent study by Springer et al. (2020) found a negative effect on female mass, a proxy for female fecundity; however, this was only present within an interaction with another variable, beetle host plant. Nevertheless, in this study we show that lifelong stress (i.e. not simply confined to the developmental period) can significantly and detrimentally influence fitness through a reduction in LRS in addition to increasing larval mortality. In addition, we also present another form of inbreeding-environment interaction, in which the control temperature of $29^{\circ} \mathrm{C}$ also produced significantly reduced eclosion probability in inbred individuals, which mirrors results from previous work by Fox et al. (2011).
Why such inbreeding-environment interactions should produce deleterious effects on fitness requires an explanation. In a series of elegant studies, Kristensen et al. (2002), Kristensen et al. (2005), Kristensen et al. (2006) found that inbred Drosophila flies were disproportionately expressing genes relating to metabolism and stress response in comparison to outbred individuals (Kristensen et al., 2005). In particular, they found that the heat-shock protein (Hsp70) was expressed at higher levels in benign laboratory conditions when individuals were inbred. Importantly, the expression of Hsp70 is associated with severe and detrimental costs to fitness (Krebs \& Feder, 1997; Kristensen et al., 2002). Additionally, when inbred flies were exposed to environmental stress through increasing temperature, they again found differential expression of several important metabolic genes in a synergistic fashion (Kristensen et al., 2006). Taken together, these results, coupled with previous research, suggests that the inbred lines here, which were exposed to both genetic and environmental stress, could be expressing a wide variety of genes that ultimately are contributing to reduced fitness. Future research should focus on understanding whether the same candidate loci found in Drosophila are expressed in C. maculatus when exposed to both environmental and genetic stress.

The exacerbated negative effects we show here, despite the exposure to the reduced environmental stress of the laboratory (Hedrick \& Kalinowski, 2000), highlights the severe and detrimental impact that global climatic changes coupled with habitat fragmentation could have on the survivability of small populations. It is therefore critically important for future conservation research to study these inbreeding-stress interactions in more complex environments using natural populations and with a wide variety of stressors. 


\section{ACKNOWLEDGMENTS}

Financial support for this project was provided by The European Research Council (ERC) GermlineAgeingSoma 724909 to AAM and by The American University of Paris to ECB. We thank AUP students Sarah Bentov-Lagman, Nadia Alamoudi, and Alexandre Dehaini for their help with data collection in the lab.

\section{CONFLICT OF INTEREST}

The authors declare no conflicts of interest.

\section{PEER REVIEW}

The peer review history for this article is available at https://publo ns.com/publon/10.1111/jeb.13899.

\section{OPEN RESEARCH BADGES}

\section{(II)}

This article has earned an Open Data Badge for making publicly available the digitally-shareable data necessary to reproduce the reported results. The data is available at https://doi.org/10.5061/ dryad.n8pk0p2vr.

\section{DATA AVAILABILITY STATEMENT}

Data is deposited in Dyrad: https://doi.org/10.5061/dryad.n8pk0 p2vr.

\section{ORCID}

Edward Ivimey-Cook iD https://orcid.org/0000-0003-4910-0443

\section{REFERENCES}

Agrawal, A. F., \& Whitlock, M. C. (2010). Environmental duress and epistasis: How does stress affect the strength of selection on new mutations? Trends in Ecology \& Evolution, 25, 450-458. https://doi. org/10.1016/j.tree.2010.05.003

Armbruster, P., \& Reed, D. H. (2005). Inbreeding depression in benign and stressful environments. Heredity, 95, 235-242. https://doi. org/10.1038/sj.hdy.6800721

Barnett, T. P., Pierce, D. W., \& Schnur, R. (2001). Detection of anthropogenic climate change in the world's oceans. Science, 292, 270-274. https://doi.org/10.1126/science.1058304

Berger, D., Stångberg, J., Baur, J., \& Walters, R. J. (2021). Elevated temperature increases genome-wide selection on de novo mutations. Proceedings of the Royal Society B: Biological Sciences, 288(1944), 20203094. https://doi.org/10.1098/rspb.2020.3094

Berger, D., Stångberg J., Grieshop K., Martinossi-Allibert I., Arnqvist G. (2017). Temperature effects on life-history trade-offs, germline maintenance and mutation rate under simulated climate warming. Proceedings of the Royal Society B: Biological Sciences, 284(1866), 20171721. https://doi.org/10.1098/rspb.2017.1721

Bijlsma, R., Bundgaard, J., \& Van Putten, W. F. (1999). Environmental dependence of inbreeding depression and purging in Drosophila melanogaster. Journal of Evolutionary Biology, 12, 1125-1137. https://doi. org/10.1046/j.1420-9101.1999.00113.x

Bilde, T., Maklakov, A. A., Meisner, K., la Guardia, L., \& Friberg, U. (2009). Sex differences in the genetic architecture of lifespan in a seed beetle: Extreme inbreeding extends male lifespan. BMC Evolutionary Biology, 9, 33. https://doi.org/10.1186/1471-2148-9-33
Blows, M. W., \& Hoffmann, A. A. (2005). A reassessment of genetic limits to evolutionary change. Ecology, 86, 1371-1384. https://doi. org/10.1890/04-1209

Both, C., Bouwhuis, S., Lessells, C. M., \& Visser, M. E. (2006). Climate change and population declines in a long-distance migratory bird. Nature, 441, 81-83. https://doi.org/10.1038/nature04539

Brooks, M. E., Kristensen, K., Benthem, K. J., Magnusson, A., Berg, C. W., Nielsen, A., Skaug, H. J., Mächler, M., \& Bolker, B. M. (2017). gImmTMB balances speed and flexibility among packages for zeroinflated generalized linear mixed modeling. $R$ Journal, 9, 378. https:// doi.org/10.32614/rj-2017-066

Charlesworth, D., \& Charlesworth, B. (1987). Inbreeding depression and its evolutionary consequences. Annual Review of Ecology and Systematics, 18, 237-268. https://doi.org/10.1146/annur ev.es.18.110187.001321

Charlesworth, D., \& Willis, J. H. (2009). The genetics of inbreeding depression. Nature Reviews Genetics, 10, 783-796. https://doi. org/10.1038/nrg2664

Davis, M. B., \& Shaw, R. G. (2001). Range shifts and adaptive responses to Quaternary climate change. Science, 292, 673-679. https://doi. org/10.1126/science.292.5517.673

East, E. M. (1908). Inbreeding in corn. Report of the Connecticut Agricultural Experiment Station, 1907, 419-428.

Fox, C. W. (1994). The influence of egg size on offspring performance in the seed beetle, Callosobruchus Maculatus. Oikos, 71(2), 321. https://doi.org/10.2307/3546280

Fox, C. W., \& Reed, D. H. (2010). Inbreeding depression increases with maternal age in a seed-feeding beetle. Evolutionary Ecology Research, 12, 961-972.

Fox, C.W., \& Reed, D. H. (2011). Inbreeding depression increases with environmental stress: An experimental study and meta-analysis. Evolution, 65, 246-258. https://doi.org/10.1111/j.1558-5646.2010.01108.x

Fox, C. W., Scheibly, K. L., Smith, B. P., \& Wallin, W. G. (2007). Inbreeding depression in two seed-feeding beetles, Callosobruchus maculatus and Stator limbatus (Coleoptera: Chrysomelidae). Bulletin of Entomological Research, 97(1), 49-54. https://doi.org/10.1017/s0007485307004737

Fox, C. W., Scheibly, K. L., Wallin, W. G., Hitchcock, L. J., Stillwell, R. C., \& Smith, B. P. (2006). The genetic architecture of life span and mortality rates: Gender and species differences in inbreeding load of two seed-feeding beetles. Genetics, 174, 763-773. https://doi. org/10.1534/genetics.106.060392

Fox, C. W., \& Stillwell, R. C. (2009). Environmental effects on sex differences in the genetic load for adult lifespan in a seed-feeding beetle. Heredity, 103, 62-72. https://doi.org/10.1038/hdy.2009.31

Fox, C. W., Stillwell, R. C., Wallin, W. G., Curtis, C. L., \& Reed, D. H. (2011). Inbreeding-environment interactions for fitness: Complex relationships between inbreeding depression and temperature stress in a seed-feeding beetle. Evolutionary Ecology, 25, 25-43. https://doi. org/10.1007/s10682-010-9376-3

Franke, K., \& Fischer, K. (2015). Inbreeding interferes with the heatshock response. Heredity, 114, 80-84. https://doi.org/10.1038/ hdy. 2014.72

Franks, S. J., \& Weis, A. E. (2008). A change in climate causes rapid evolution of multiple life-history traits and their interactions in an annual plant. Journal of Evolutionary Biology, 21, 1321-1334. https://doi. org/10.1111/j.1420-9101.2008.01566.x

Fritzsche, K., \& Arnqvist, G. (2013). Homage to Bateman: Sex roles predict sex differences in sexual selection. Evolution, 67, 1926-1936. https://doi.org/10.1111/evo.12086

Gibbs, J. P. (2001). Demography versus habitat fragmentation as determinants of genetic variation in wild populations. Biological Conservation, 100, 15-20. https://doi.org/10.1016/S0006-3207(00)00203-2

Gottfried, M., Pauli, H., Futschik, A., Akhalkatsi, M., Barančok, P., Benito Alonso, J. L., Coldea, G., Dick, J., Erschbamer, B., Fernández Calzado, 
M. R., Kazakis, G., Krajči, J., Larsson, P., Mallaun, M., Michelsen, O., Moiseev, D., Moiseev, P., Molau, U., Merzouki, A., ... Grabherr, G. (2012). Continent-wide response of mountain vegetation to climate change. Nature Climate Change, 2, 111-115. https://doi.org/10.1038/ nclimate1329

Green, R., \& Painter, P. R. (1975). Selection for fertility and development time. The American Naturalist, 109, 1-10. https://doi. org/10.1086/282969

Hartig, F. (2020). DHARMa: Residual diagnostics for hierarchical (multi-level / mixed) regression models. $R$ package.

Hedrick, P. W., \& Kalinowski, S. T. (2000). Inbreeding depression in conservation biology. Annual Review of Ecology and Systematics, 31, 139162. https://doi.org/10.1146/annurev.ecolsys.31.1.139

Hickling, R., Roy, D. B., Hill, J. K., Fox, R., \& Thomas, C. D. (2006). The distributions of a wide range of taxonomic groups are expanding polewards. Global Change Biology, 12, 450-455. https://doi. org/10.1111/j.1365-2486.2006.01116.x

Ho, J., Tumkaya, T., Aryal, S., Choi, H., \& Claridge-Chang, A. (2019). Moving beyond $\mathrm{P}$ values: Data analysis with estimation graphics. Nature Methods, 16, 565-566. https://doi.org/10.1038/s4159 2-019-0470-3

Holt, R. D. (1990). The microevolutionary consequences of climate change. Trends in Ecology \& Evolution, 5, 311-315. https://doi. org/10.1016/0169-5347(90)90088-U

Huisman, J., Kruuk, L. E. B., Ellis, P. A., Clutton-Brock, T., \& Pemberton, J. M. (2016). Inbreeding depression across the lifespan in a wild mammal population. Proceedings of the National Academy of Sciences of the United States of America, 113, 3585-3590. https://doi.org/10.1073/ pnas.1518046113

Janzen, D. H. (1967). Why mountain passes are higher in the tropics. The American Naturalist, 101, 233-249. https://doi.org/10.1086/282487

Jiguet, F., Gadot, A.-S., Julliard, R., Newson, S. E., \& Couvet, D. (2007). Climate envelope, life history traits and the resilience of birds facing global change. Global Change Biology, 13(8), 1672-1684. https://doi. org/10.1111/j.1365-2486.2007.01386.x

Keller, L. F., \& Waller, D. M. (2002). Inbreeding effects in wild populations. Trends in Ecology \& Evolution, 17, 230-241. https://doi.org/10.1016/ S0169-5347(02)02489-8

Kirkpatrick, M., \& Jarne, P. (2000). The effects of a bottleneck on inbreeding depression and the genetic load. The American Naturalist, 155, 154-167. https://doi.org/10.1086/303312

Krebs, R. A., \& Feder, M. E. (1997). Deleterious consequences of Hsp70 overexpression in Drosphilla melanogaster larvae. Cell Stress and Chaperones, 2, 60-71. https://doi.org/10.1379/14661268(1997)002<0060:DCOHOI>2.3.CO;2

Kristensen, T. N., Dahlgaard, J., \& Loeschcke, V. (2002). Inbreeding affects Hsp70 expression in two species of Drosophila even at benign temperatures. Evolutionary Ecology Research, 4, 1209-1216.

Kristensen T. N., Sørensen P., Kruhøffer M., Pedersen K. S., Loeschcke V. (2005). Genome-wide analysis on inbreeding effects on gene expression in Drosophila melanogaster. Genetics, 171(1), 157-167. https:// doi.org/10.1534/genetics.104.039610

Kristensen T. N., Sørensen P., Pedersen K. S., Kruhøffer M., Loeschcke V. (2006). Inbreeding by environmental interactions affect gene expression in Drosophila melanogaster. Genetics, 173(3), 1329-1336. https://doi.org/10.1534/genetics.105.054486

Leimu, R., Mutikainen, P., Koricheva, J., \& Fischer, M. (2006). How general are positive relationships between plant population size, fitness and genetic variation? Journal of Ecology, 94(5), 942-952. https://doi. org/10.1111/j.1365-2745.2006.01150.x

Lenth, R., Singmann, H., Love, J., Buerkner, P., \& Herve, M. (2019). emmeans: Estimated marginal means, aka least-squares means (version 1.3. 4).

Leslie, P. H. (1945). On the use of matrices in certain population mathematics. Biometrika, 33, 183-212. https://doi.org/10.1093/biomet/ 33.3.183
Liao, W., \& Reed, D. H. (2009). Inbreeding-environment interactions increase extinction risk. Animal Conservation, 12, 54-61. https://doi. org/10.1111/j.1469-1795.2008.00220.x

Lind, M. I., Zwoinska, M. K., Andersson, J., Carlsson, H., Krieg, T., Larva, T., \& Maklakov, A. A. (2020). Environmental variation mediates the evolution of anticipatory parental effects. Evolution Letters, 4, 371381. https://doi.org/10.1002/evl3.177

Magnusson, A., Skaug, H. J., Nielsen, A., Berg, C., Kristensen, K., Maechler, M., van Bentham, K., Bolker, B., Brooks, M., \& Brooks, M. M. (2019). Package 'glmmTMB'. R package version 0.1 .

Maklakov, A. A., \& Fricke, C. (2009). Sexual selection did not contribute to the evolution of male lifespan under curtailed age at reproduction in a seed beetle. Ecological Entomology, 34, 638-643. https://doi. org/10.1111/j.1365-2311.2009.01113.x

Messina, F. J. (1991). Competitive interactions between larvae from divergent strains of the cowpea weevil (Coleoptera: Bruchidae). Environmental Entomology, 20, 1438-1443. https://doi.org/10.1093/ ee/20.5.1438

Messina, F. J., \& Slade, A. F. (1999). Expression of a life-history trade-off in a seed beetle depends on environmental context. Physiological Entomology, 24, 358-363. https://doi.org/10.1046/ j.1365-3032.1999.00151.x

Muñoz, N. J., Farrell, A. P., Heath, J. W., \& Neff, B. D. (2015). Adaptive potential of a Pacific salmon challenged by climate change. Nature Climate Change, 5, 163-166. https://doi.org/10.1038/nclimate2473

Norberg, J., Urban, M. C., Vellend, M., Klausmeier, C. A., \& Loeuille, N. (2012). Eco-evolutionary responses of biodiversity to climate change. Nature Climate Change, 2, 747-751. https://doi.org/10.1038/ nclimate1588

Opdam, P., \& Wascher, D. (2004). Climate change meets habitat fragmentation: Linking landscape and biogeographical scale levels in research and conservation. Biological Conservation, 117, 285-297. https://doi. org/10.1016/j.biocon.2003.12.008

Orr, H. A., \& Betancourt, A. J. (2001). Haldane's sieve and adaptation from the standing genetic variation. Genetics, 157, 875-884. https:// doi.org/10.1093/genetics/157.2.875

Pachauri, R. K., Allen, M. R., Barros, V. R., Broome, J., Cramer, W., Christ, R., Church, J. A., Clarke, L., Dahe, Q., Dasgupta, P., Dubash, N. K., Edenhofer, O., Elgizouli, I., Field, C. B., Forster, P., Friedlingstein, P., Fuglestvedt, J., Gomez-Echeverri, L., Hallegatte, S., ... van Ypserle, J.-P. (2014). Climate change 2014: Synthesis report. Contribution of Working Groups I, II and III to the fifth assessment report of the Intergovernmental Panel on Climate Change. IPCC.

Pearson, R. G., Stanton, J. C., Shoemaker, K. T., Aiello-Lammens, M. E., Ersts, P. J., Horning, N., Fordham, D. A., Raxworthy, C. J., Ryu, H. Y., McNees, J., \& Akçakaya, H. R. (2014). Life history and spatial traits predict extinction risk due to climate change. Nature Climate Change, 4, 217-221. https://doi.org/10.1038/nclimate2113

Pereira, H. M., Navarro, L. M., \& Martins, I. S. (2012). Global biodiversity change: The bad, the good, and the unknown. Annual Review of Environment and Resources, 37, 25-50. https://doi.org/10.1146/ annurev-environ-042911-093511

R Core Team. (2019). $R$ version 3.6. 2: A language and environmental for statistical computing.

Roff, D. A. (2002). Inbreeding depression: Tests of the overdominance and partial dominance hypotheses. Evolution, 56, 768-775. https:// doi.org/10.1111/j.0014-3820.2002.tb01387.x

Rogell, B., Widegren, W., Hallsson, L. R., Berger, D., Björklund, M., \& Maklakov, A. A. (2014). Sex-dependent evolution of life-history traits following adaptation to climate warming. Functional Ecology, 28, 469-478. https://doi.org/10.1111/1365-2435.12179

Root, T. L., Price, J. T., Hall, K. R., Schneider, S. H., Rosenzweig, C., \& Pounds, J. A. (2003). Fingerprints of global warming on wild animals and plants. Nature, 421, 57-60. https://doi.org/10.1038/nature01333

Rosenzweig, C., Karoly, D., Vicarelli, M., Neofotis, P., Wu, Q., Casassa, G., Menzel, A., Root, T. L., Estrella, N., Seguin, B., Tryjanowski, P., Liu, 
C., Rawlins, S., \& Imeson, A. (2008). Attributing physical and biological impacts to anthropogenic climate change. Nature, 453, 353-357. https://doi.org/10.1038/nature06937

Seebacher, F., White, C. R., \& Franklin, C. E. (2015). Physiological plasticity increases resilience of ectothermic animals to climate change. Nature Climate Change, 5, 61-66. https://doi.org/10.1038/nclim ate 2457

Sibly, R., \& Calow, P. (1986). Why breeding earlier is always worthwhile. Journal of Theoretical Biology, 123, 311-319. https://doi.org/10.1016/ S0022-5193(86)80246-6

Sibly, R., Calow, P., \& Nichols, N. (1985). Are patterns of growth adaptive? Journal of Theoretical Biology, 112, 553-574. https://doi.org/10.1016/ S0022-5193(85)80022-9

Springer, A. L., Messina, F. J., \& Gompert, Z. (2020). Measuring the effect of environmental stress on inbreeding depression alone obscures the relative importance of inbreeding-stress interactions on overall fitness in Callosobruchus maculatus. Evolutionary Applications, 13(10), 2597-2609. https://doi.org/10.1111/eva.13060

Stubben C., Milligan B. (2007). Estimating and Analyzing Demographic Models Using thepopbioPackage inR. Journal of Statistical Software, 22, 11. https://doi.org/10.18637/jss.v022.i11

Therneau, T. (2012) Mixed effects Cox models. R package version 2.2-3. http://www.cran.R\%2010project.org/package $=$ coxme.Oikos

Thomas, C. D. (2010). Climate, climate change and range boundaries. Diversity and Distributions, 16(3), 488-495. https://doi. org/10.1111/j.1472-4642.2010.00642.x

Trisos, C. H., Merow, C., \& Pigot, A. L. (2020). The projected timing of abrupt ecological disruption from climate change. Nature, 580, 496501. https://doi.org/10.1038/s41586-020-2189-9

Tylianakis, J. M., Didham, R. K., Bascompte, J., \& Wardle, D. A. (2008). Global change and species interactions in terrestrial ecosystems. Ecology Letters, 11, 1351-1363. https://doi.org/10.1111/ j.1461-0248.2008.01250.x

Visser, M.E.,Perdeck, A.C., Balen, J.H.V., \& Both, C. (2009). Climate change leads to decreasing bird migration distances. Global Change Biology, 15, 1859-1865. https://doi.org/10.1111/j.1365-2486.2009.01865.x
Visser, M. E., te Marvelde, L., \& Lof, M. E. (2012). Adaptive phenological mismatches of birds and their food in a warming world. Journal of Ornithology, 153, 75-84. https://doi.org/10.1007/s1033 6-011-0770-6

Visser, M. E., van Noordwijk, A. J., Tinbergen, J. M., \& Lessells, C. M. (1998). Warmer springs lead to mistimed reproduction in great tits (Parus major). Proceedings of the Royal Society of London. Series B: Biological Sciences, 265(1408), 1867-1870. https://doi.org/10.1098/ rspb.1998.0514

Wickham H. (2011). ggplot2. Wiley Interdisciplinary Reviews: Computational Statistics, 3(2), 180-185. https://doi.org/10.1002/wics.147

Willi, Y., Van Buskirk, J., \& Hoffmann, A. A. (2006). Limits to the adaptive potential of small populations. Annual Review of Ecology, Evolution, and Systematics, 37, 433-458.

Yun, L., \& Agrawal, A. F. (2014). Variation in the strength of inbreeding depression across environments: Effects of stress and density dependence. Evolution, 68, 3599-3606. https://doi.org/10.1111/ evo.12527

\section{SUPPORTING INFORMATION}

Additional supporting information may be found online in the Supporting Information section.

How to cite this article: Ivimey-Cook, E., Bricout, S., Candela, V., Maklakov, A. A., \& Berg, E. C. (2021). Inbreeding reduces fitness of seed beetles under thermal stress. Journal of Evolutionary Biology, 00, 1-11. https://doi.org/10.1111/ jeb.13899 